\title{
Space Exploration of Comets and the Evolution of Amateur-Professional Cooperation
}

\author{
A.-C. Levasseur-Regourd \\ Université Paris IV, Service d'Aéronomie, BP.3, \\ F-91371 Verrières le Buisson, France
}

\section{Introduction}

In 1985-86 when spaceprobes flew past $\mathrm{P} /$ Giacobini-Zinner and $\mathrm{P} / \mathrm{Halley}$, many amateurs observed these comets and submitted their results to national or international (IHW) organisations. Their visual, photographic, photometric and spectroscopic observations made a contribution to scientific knowledge. It is pertinent to ask if space programmes under consideration will allow similar cooperation to be continued.

\section{Possibilities for the Exploration of Small Bodies in the Solar System}

The least uncertain project is that of another cometary fly-past by GIOTTO. Following orbital corrections made between 1986 March 19 and April 2, $\left(\Delta \mathrm{V}=115 \mathrm{~ms}^{-1}\right)$, the European probe should pass $22300 \mathrm{~km}$ from the Earth on 1990 July 2 . The gravitational assist from our planet should then put it onto an orbit to pass $\mathrm{P} / \mathrm{Hartley} 2$, P/du Toit-Hartley or P/Grigg-Skjellerup (1992 July 10). This last comet appears to be the most desirable target; although the final decision will not be taken until autumn 1989, recommendations have been made (Morley, 1986) for an international astrometric campaign.

There is also a lot of discussion about the American CRAF (Cometary Rendezvous Asteroid Fly-by) mission. NASA envisages using a spacecraft of the new Mariner Mark II series to follow the changes in activity of P/Wild 2, P/Kopff or, more probably, P/Tempel2. Launch will take place in 1993 February; after using the gravitational assistance of the Earth and Mars, and passing the minor planet Hestia, the rendez-vous will last from 1996 to 1999 (Neugebauer, 1987). CRAF has not yet received official approval; but its experiments have been chosen, and a call for astrometric, photometric and spectroscopic observations have been made.

Other missions are still being studied. The American GALILEO probe, grounded by the Space Shuttle disaster, may fly past a minor planet before arriving at Jupiter. The VESTA Franco-Soviet-European vehicles (Perret, 1987) could fly past 5 minor planets and one comet (P/du Toit-Neujmin-Delporte?), between 1994 and 2000. Finally, there is the possibility, at the beginning of the 21 st century, of a CNSR (Comet Nucleus Sample Return) mission, with the return of samples obtained either from the coma or better, from the nucleus of a comet (Schwehm, 1986; Eberhardt, 1986). 


\section{Comets Grigg-Skjellerup and Tempel 2}

It is therefore these two comets that are of interest to space agencies. They are shortperiod objects belonging to Jupiter's family. They are relatively old, low in dust, faint, and thus quite different to Halley. P/Grigg-Skjellerup passed perihelion on 1987 June 18 (magnitude $\approx 13$ ) - specially for this Colloquium - and P/Tempel 2 in 1988 September (magnitude $\approx 10$ ) and again in 1993 December (Table 1).

Table 1. Orbital elements (Marsden, 1986)

\begin{tabular}{lllllllll}
\hline Comet & $\mathrm{T}$ & $\mathrm{q}(\mathrm{AU})$ & $\mathrm{e}$ & $\mathrm{i}\left({ }^{\circ}\right)$ & $\Omega\left(^{\circ}\right)$ & $\omega\left(^{\circ}\right)$ & $\mathrm{P}(\mathrm{yrs})$ & $\mathrm{NGF}$ \\
\hline G.-S. & 1982 May 15 & $\mathbf{0 . 9 8 9}$ & 0.666 & 21.1 & 212.6 & 359.3 & 5.09 & $+\mathbf{0 . 0 1 ; - 0 . 0 0 1 1}$ \\
Tempel 2 & 1983 June 1 & 1.381 & 0.545 & 12.4 & 119.2 & 190.9 & 5.29 & $+0.05 ;+0.0016$
\end{tabular}

The success of future missions depends on better knowledge of the evolution of orbits (the problem of non-gravitational forces) and of both the orientation and the rotational period of the nucleus (position of active areas); which explains the importance of observations made by professionals and advanced amateurs.

\section{The Role of Amateur Astronomers}

Amateurs that have been trained in rigorous methods and having access to powerful instruments have an essential role in astrometry and photometry of comets (or minor planets) that may be explored between now and the end of the century. The computing facilities that most amateurs possess allow them to carry out preliminary analysis of their observations (correlation with ephemerides, search for periodicity, etc.). But the work of amateurs who just observe minor planets, meteor showers, or "good" comets, although seemingly less important, should not be under-estimated. The space exploration of the Solar System represents a "new frontier", in which amateurs, with their love and curiosity for the sky, should be the first to participate.

\section{References}

Eberhardt, P. et al.: in Exploration of Halley's Comet, ESA SP 250, 243, 1986

Marsden, B.A.: Catalogue of Cometary Orbits, IAU, 1986

Morley, T.A.: GIOTTO study note 61, ESOC, 1986

Neugebauer, M.: in Diversity and similarity of comets, ESA SP 278, in press, 1987

Perret, A.: Rapport de phase A Vesta, CNES, 1987

Schwehm, G.H., ed.: Comet nucleus sample return, ESA SP 249, 1986 